\section{A holistic definition of healthy traditional harvest practices for rural Indigenous communities in Interior Alaska}

\author{
Krista M. Heeringa a * \\ University of Alaska Fairbanks
Orville Huntington ${ }^{b}$
Huslia Tribal Member and Tanana Chiefs
Conference (TCC)

Brooke Woods ${ }^{\mathrm{c}}$

Rampart Tribal Member and TCC

\author{
Special JAFSCD Issue \\ Indigenous Food Sovereignty in North America \\ sponsored by
}

\section{Swette Center for Sustainable Food Systems} Arizona State University

Submitted January 15, 2019 / Revised March 8 and April 5, 2019 / Accepted April 7, 2019 / Published online October 15, 2019

Citation: Heeringa, K. M., Huntington, O., Woods, B., Chapin, F. S., III, Hum, R. E., Brinkman, T. J., \& Workshop Participants. (2019). A holistic definition of healthy traditional harvest practices for rural Indigenous communities in Interior Alaska. Journal of Agriculture, Food Systems, and Community Development, 9(2Suppl. 2), 115-129. https://doi.org/10.5304/jafscd.2019.09B.009

Copyright (C) 2019 by the Authors. Published by the Lyson Center for Civic Agriculture and Food Systems. Open access under CC-BY license.

\begin{abstract}
Traditional harvest practices of the harvesting and sharing of fish, wildlife, and other wild resources are an integral source of food security that support

a * Corresponding author: Krista M. Heeringa, Community Partnerships for Self Reliance, University of Alaska Fairbanks (UAF); 2160 Koyukuk Drive; Fairbanks AK 99775 USA; +1-907-474-1880; kmheeringa@alaska.edu

b Orville Huntington, Wildlife and Parks, Tanana Chiefs Conference (TCC); 122 1st Ave.; Fairbanks AK 99701 USA; +1-907-452-8251; orville.huntington@tananachiefs.org

${ }^{\mathrm{c}}$ Brooke Woods, Hunting and Fishing Task Force, TCC; 122 1st Ave.; Fairbanks AK 99701 USA; +1-907-452-8251; Brooke.Wright@,tananachiefs.org

${ }^{\mathrm{d}}$ F. Stuart Chapin III, Professor Emeritus, Ecology, Institute of Arctic Biology, UAF; P.O. Box 757000; Fairbanks, AK 99775 USA; +1-907-590-9672; fschapiniii@alaska.edu

e Richard E. Hum, Assistant Professor of Cross Cultural Studies, UAF; Center for Cross Cultural Studies; P.O. Box 756730; Fairbanks, AK 99775 USA; +1-907-474-5897; rehum@alaska.edu

f Todd J. Brinkman, Assistant Professor of Wildlife Ecology, Institute of Arctic Biology, UAF; P.O. Box 757000; Fairbanks, AK 99775 USA; +1-907-474-7139; tibrinkman@alaska.edu
\end{abstract}

\author{
F. Stuart Chapin III, ${ }^{\mathrm{d}}$ Richard E. Hum, ${ }^{\mathrm{e}}$ and \\ Todd J. Brinkman ${ }^{\mathrm{f}}$ \\ University of Alaska Fairbanks
}

Workshop Participants $g$ 
of Indigenous communities in Interior Alaska. Many significant changes, including climate change, are impacting this way of life and challenging secure access to foods vital for sustenance and cultural preservation. We use a case study approach to develop a holistic and place-based definition of traditional harvest practices of Indigenous communities in rural Interior Alaska that expands upon commonly accepted definitions of food security. This definition emphasizes the role of ecological health, culture, and decision-making power in strengthening food security and sovereignty. We also highlight how multistakeholer partnerships foster capacity building that can support communities in their efforts to advocate for food security and sovereignty.

\section{Keywords}

Indigenous Food Systems, Wild Foods, Interior Alaska, Traditional Livelihoods, Food Security, Food Sovereignty, Climate Change

\section{Introduction}

\section{Changing Food Systems}

The interwoven relationships between ecological systems, livelihoods, culture, well-being, and wild foods of Indigenous communities in the Arctic are well-documented (Duhaime, 2002; Inuit Circumpolar Council-Alaska [ICC], 2015; Loring \& Gerlach, 2009; Zagoskin, 1967). These communities have survived for millennia in a harsh climate through their attunement to the landscape and to the fish, game, and other wild resources on which they relied (Kawagley, 2006; Krupnik, 1993). This deep relationship with the land supported cultural stability that gave rise to distinct cultures related to place (Berkes, 2012). At one time, Arctic Indigenous communities had food sovereignty and traditional trade practices were common. In Alaska, forces of social and economic change, beginning with the Russian fur trade in the mid-1800s and accelerating with the discovery of gold in the late 1800s and early 1900s, dramatically changed the food systems, livelihoods, and social and governance structures of Indigenous communities (Foote, 1965). Economic change came in many forms that partially replaced long-standing barter and trade systems with a cash economy. An influx of gold seekers and settlers brought new forms of commerce. In some cases, this aided harvest activities through the introduction of new technologies such as fish wheels, prop motors, and rifles. However, these new technologies and the influx of people also increased competition for, and overharvesting of, wild resources (Loyens, 1966). Foreign populations brought epidemics that decimated Indigenous populations in Alaska. The most devastating wave of sickness occurred in 1900. Indigenous communities throughout western, interior, and northern Alaska lost an estimated 25 to 50 percent of their members within a single year (Wolfe, 1982), and many surviving children were sent to newly constructed boarding schools (Loyens, 1966). In addition to displacement of youth caused by epidemics, around the turn of the century the United States adopted policies that removed Indigenous youth from their communities and sent them to boarding schools with the expressed intention of assimilating them into Euro-American culture and severing connections to their homelands and traditions, including traditional food (Coté, 2016). These policies have had lasting impacts among Indigenous communities in Alaska.

New forms of governance were institutionalized after Alaska statehood was ratified in 1959. The passage of the Alaska Native Claims Settlement Act (ANCSA) in 1971 extinguished aboriginal hunting and fishing rights (ANCSA, 1971). The passage of the Alaska National Interests Land Conservation Act (ANILCA) in 1980 did little to restore the strong Indigenous relationship with the land and tradition of stewardship because it failed to protect access to wild foods based on ethnicity (ANILCA, 1980; Wheeler \& Thornton, 2005). Today, competing state and federal jurisdictions related to the management of wild resources have given rise to a complicated dual management system that challenges the food security of Indigenous communities. For example, preferential harvest is granted to rural communities on federal land, but not on state land. Often communities are surrounded by a patchwork of state and federal lands that have different rules for resource management and harvest of wild resources (Ristroph, 2018; Wheeler \& Thornton, 2005). 


\section{Climate Change Presents New Challenges}

In addition to economic, social, and political change, accelerating environmental changes associated with climate warming add a layer of complexity and vulnerability to the harvesting of wild foods (Brinkman, Hansen, Chapin, Kofinas, BurnSilver, \& Rupp, 2016). Climate assessments have shown warming in the Arctic that is about twice the global average (Chapin et al., 2014, Comiso \& Hall, 2014). Indigenous communities experience impacts from this warming in a number of ways. For example, frozen rivers are important travel corridors for hunting, trapping, and wood harvesting. Warmer winters have led to later freeze-up and earlier break-up of rivers in addition to longer time that rivers are unsafe to travel on, thus inhibiting access to harvest resources (Brown, Brinkman, Verbyla, Brown, Cold, \& Hollingsworth, 2018). These changes influence not only human movement but also the migration of wildlife, such as caribou, on which communities rely (Leblond, St-Laurent, \& Côté, 2016).

In the past, reliable environmental cues such as the timing of the seasons and consistency in fish, bird, and wildlife migration supported cultural stability. Flexibility and innovation within the social and governance structures of Indigenous communities supported a robust knowledge systemhereafter referred to as Traditional Ecological Knowledge (TEK) — that strengthened capacity to adapt to significant environmental variability (Barnhardt \& Kawagley, 2005; Pearce, Ford, Wilcox, \& Smit, 2014). With the rate of environmental change, the landscape is becoming less familiar to the people that have always known it well, and TEK is becoming less reliable (Cochran et al., 2013; Pearce et al., 2014). For example, coauthor Huntington recalls a well-known bear den located near his home community of Huslia. Knowledge of the den was passed down for generations. It was located on a thermokarst ridge, which is now the location of wetlands and dry lakes and the den no longer exists. Within one genera- tion this past knowledge became obsolete (Huntington \& Watson, 2012). While the Intergovernmental Panel on Climate Change asserts that climate change is one of the most significant challenges facing the globe in the current century (Larsen et al., 2014), Indigenous communities will disproportionately experience the impacts from climate change, due to not only their strong reliance on the environment for their livelihoods but also the legacies of colonialism that have challenged the perpetuation of their way of life (Ford et al., 2018; McNeely, 2011).

Despite these challenges, reliance on and sharing of fish, wildlife, and other harvested resources continues to be an integral source of food security and cultural identity for Indigenous Alaska communities. However, because of current challenges related to climate change, cultural disruptions, changing economic opportunity, and a complex management system, there is an increasing need for new creative forms of learning and knowledge distribution that can effectively support communitybased adaptations. Community-based adaptation to climate change should be a "community-led process, based on communities' priorities, needs, knowledge, and capacities, which should empower people to plan for and cope with the impacts of climate change" (Reid, Mozaharul, Berger, Cannon, Huq, \& Milligan, 2009, p. 13). Relevant community-based adaptations must consider the central role that harvest practices continue to play in supporting the livelihoods, health, wellbeing, and cultural identity of Indigenous communities.

\section{Commonly Accepted Definitions for Food Security \\ Commonly accepted definitions of food security ${ }^{1}$ largely ignore the interdependence of cultural iden- tity, traditional knowledge systems, governance structures, and stable environmental conditions that are needed to maintain Indigenous food sys- tems (Anderson, 1990; Food and Agriculture Organization of the United Nations [FAO], 2006). By contrast, definitions of food sovereignty}

\footnotetext{
${ }^{1}$ The U.S. Department of Agriculture (USDA) and the Food and Agriculture Organization of the United Nations (FAO) define food secure households as "access by all members at all times to enough food for an active, healthy life. Food security includes at a minimum: The ready availability of nutritionally adequate and safe foods [and the] assured ability to acquire acceptable foods in socially acceptable ways" (Anderson, 1990, p. 1558S).
} 
broaden this definition by placing a greater emphasis on the right of communities and nation-states to define and protect their own food systems (Wittman \& Blesh, 2017). The Declaration of Nyéléni, developed by 500 delegates from 80 countries, states that "food sovereignty is the right of peoples to healthy and culturally appropriate food produced through ecologically sound and sustainable methods, and their right to define their own food and agricultural systems" (Nyéléni Forum on Food Sovereignty, 2007). Discourse on Indigenous food sovereignty expands this definition by emphasizing the unique relationship Indigenous peoples have to the land and their reliance on it for foods that are both culturally and spiritually significant. Because these relationships are unique to different geographic areas and cultures, developing a definition of Indigenous food sovereignty that encompasses this diversity is problematic (Coté, 2016; Weiler, Hergesheimer, Brisbois, Wittman, Yassi, \& Spiegel, 2014).

The overall goal of this research is to provide, through a case study, a holistic and place-based definition of food security and food sovereignty that supports community-based adaptations that can facilitate modification of policies that better align with the perspectives of Indigenous communities in Alaska. Our specific objective is to build on the food security framework developed by the Inuit Circumpolar Council (ICC, 2015). We show its broader relevance to Athabascan communities in Interior Alaska through the collaborative work developed through a multistakeholder group consisting of university, tribal, nonprofit, and agency partners.

The ICC exists to provide a unified voice for the Alaska Inuit and serves as a Permanent Participant in the UN Arctic Council, an intergovernmental forum created to address issues faced by Arctic governments and Indigenous Arctic communities (ICC, 2015). This is how the ICC defines Inuit food sovereignty:

The right of Alaskan Inuit to define their own hunting, gathering, fishing, land, and water policies; the right to define what is sustainably, socially, economically, and culturally appropriate for the distribution of food and to maintain ecological health; the right to obtain and maintain practices that ensure access to tools needed to obtain, process, store, and consume traditional foods. Food sovereignty is a necessity to support and maintain the six dimensions of food security 1) Availability, 2) Inuit Culture, 3) Decision-Making Power, 4) Health and Wellness, 5) Stability, and 6) Accessibility. (ICC, 2015, p. 35)

We aim to compare this existing food security framework with the experience of rural Indigenous communities in Interior Alaska.

\section{Methods}

\section{Multistakeholder Partnerships}

In 2016, Community Research Partnerships for Sustainable Traditional Harvest Practices, hereafter referred to as (CRP), was initiated by the University of Alaska Fairbanks (UAF). The partnership focused on developing respectful research relationships between university and community partners that supported community-based adaptations in response to social, ecological, and environmental change impacting traditional harvest practices. The program was formed in collaboration with tribal groups from Interior Alaska that include the Anvik Tribal Council, Nulato Tribal Council, Koyukuk Tribal Council, Ruby Tribal Council, Venetie Tribal Council, tribal nonprofits including the Council of Athabascan Tribal Governments (CATG) and Tanana Chiefs Conference (TCC), and the Alaska Department of Fish \& Game (ADF\&G). Interior Alaska encompasses 11 distinct Athabascan or Dene language and cultural groups including Ahtna, Dena'ina, Deg Xinag, Holikachuk, Koyukon, Kolchan, Upper Tanana, Lower Tanana, Han, and Gwich'in (Krauss, 1982). Within this region there are 38 federally recognized tribes. Tribes within this region have representation in one or both of the tribal consortia TCC and CATG.

There is a long legacy of research relationships in the state of Alaska that have not only dismissed the knowledge, experience, and relationship of Indigenous peoples to their homelands, but also put Indigenous peoples and their homelands in 
jeopardy in the name of scientific experimentation and progress (Naske \& Hunt, 1978; National Research Council, Committee on Evaluation of 1950s Air Force Human Health Testing in Alaska Using Iodine-131, 1996; North Slope Borough Science Advisory Committee, 1993). Given the impact of these past experiences, establishing research relationships built on mutual respect and reciprocity was paramount in guiding the partnership design and process. It was also central for ensuring that research outcomes supported communities in their vision for food security and sovereignty and did not simply reinforce institutionalized power imbalances that undermine empowerment (Kepkiewicz et al., 2015; Loring \& Gerlach, 2015). Specifically, the CRP initiative drew heavily from recommendations on best practices and codes of ethics while developing the initial plan for community-engaged research. Important references included the Alaska Native Science Commission Code of Research Ethics (ANSC, 1997), the National Congress of American Indians best practices guide, 'Walk softly and listen carefully': Building research relationships with tribal communities (NCIA, 2012), and the Alaska Native Knowledge Network Guidelines for Respecting Cultural Knowledge (ANKN, 2000).

Building strong research partnerships that supported community-based adaptations was a guiding objective of the CRP initiative. Beginning in early 2016, CRP wrote to all tribal councils, cities, and village corporations within the TCC region that had a year-round population $(N=38)$ and invited them to participate in the CRP initiative. Eight tribal councils and two village corporations returned an expression of interest. After further follow-up, one tribal council and one village corporation decided not to advance further in the partnership process. Project teams formed that consisted of various combinations of community leadership and university faculty, students, agency personnel, and the CRP coordinator. During the initial community visits, community leaders were asked to identify current challenges affecting their traditional harvest practices. These conversations informed the questions and goals behind each research partnership.

Focus areas of research partnerships determined by community and tribal-council input included a community assessment of food security and sovereignty, a traditional place-name mapping initiative, research that investigated the impacts of climate variables on moose harvest success, local versus non-local hunting competition, and the impacts of climate change on berry variability and availability. After two years, all participants and collaborators who participated in the CRP initiative came to a workshop in Fairbanks in May 2018. The purpose of the workshop was to share perspectives, challenges, and opportunities related to healthy traditional harvest practices, synthesize research findings, and to reflect as a group on how individual partnerships supported communitybased adaptations. Two main techniques were used to synthesize workshop participant perspectives: a system model of contemporary perceptions of traditional harvest practices using a collaborativenetwork mapping activity, and a trend-mapping exercise (Parkhurst \& Preskill, 2016) that recorded the positive and negative changes affecting traditional harvest practices in Interior Alaska.

\section{Rural Interior Alaska Community-based Adaptation Workshop}

A total of 34 participants representing six communities, four university departments, and four organizations or agencies attended the workshop. These included the research affiliates and community representatives heavily involved with individual research efforts. Also included were knowledgable experts in the management of hunting, fishing, and gathering activities, experienced Indigenous hunters, fishers, and gatherers, an Elder advisor, and experts in building and strengthening multistakeholder partnerships. Given the limited participation of Interior communities $(n=6)$, results from this workshop should not be considered representative of the entire region although they may offer insights into areas of critical vulnerability and potential strategies for food security and food sovereignty that are more broadly relevant to the region.

Deliberate attention was given to address power imbalances related to gender, ethnicity, and education level that, if not addressed, can undermine inclusivity, legitimacy, and trust-building that are necessary practices in knowledge co-production 
(Djenontin \& Meadow 2018; Sbicca, 2015). They were addressed in part by emphasizing that each individual had important contributions to make through their lived experiences. Everyone, regardless of whether they were a hunter, professor, manager, or community member, was encouraged to share their unique perspective. We also utilized workshop agreements adapted from the First Alaskans Institute (FAI) that establish ground rules for interpersonal interactions that are based in Alaska Native culture and practices (FAI, 2014).

This two-and-a-half-day workshop had three major objectives: (1) to develop a common understanding around key concepts related to healthy traditional harvest practices, vulnerability, adaptive strategies, and resilience; (2) identify major changes (both positive and negative) affecting traditional harvest practices in rural Interior Alaska; and (3) identify if or how individual research efforts supported community-based adaptations.

We accomplished the first objective by identifying attributes and a system boundary of healthy traditional harvest practices among Indigenous communities in Interior Alaska based on the perceptions and experiences of workshop participants. We did this by asking each participant as soon as they arrived on Day 1 to write down three to six single words or word pairs that described what strong and healthy traditional harvest practices meant to them. These words and word pairs were then used to create a network that linked individual participants to the words and word pairs. We used the network as a visual tool to lead a discussion that elaborated what participants meant by their word selections. As similarities and themes emerged among different word uses, we grouped and clustered different parts of the original network to show the shared understanding of what participants understood as a healthy traditional harvest system. Ten thematic areas were identified and built upon in the rest of the workshop. Two additional themes were added during a following exercise. These themes were closely related to those developed by the ICC, showing the similarities between perceptions of food sovereignty and security frameworks between the Arctic and Interior regions.

Once we identified the system boundary for healthy traditional harvest practices, we used an adapted trend-mapping method to explore positive and negative changes to this system (Parkhurst \& Preskill, 2016). We did this by asking workshop participants to describe five to seven key changes (both positive and negative) that they thought were influencing healthy traditional harvest practices of Indigenous communities in Interior Alaska, with an emphasis on the last 10 years. Positive impacts were those that supported, strengthened, or increased access to harvest, or were examples of adaptations to stressors. Negative impacts were those that hindered, weakened, or decreased access to harvest practices, or increased the vulnerability of harvest practices. After each participant identified changes they considered significant, they were asked to cluster the changes around the attributes of healthy traditional harvest practices that the change was most closely tied to. Responses in each cluster were further reduced by combining similar or duplicative changes, while unique changes were kept. Workshop participants performed the reduction process together to reach a consensus on cluster categories.

\section{Highlighting the Limitations of the Findings}

Methods used in this research primarily originated in western paradigms of research, and thus have limitations and weaknesses. For example, these methods do not fully recognize that Indigenous Knowledge methodologies are grounded in place, shared identity, spirituality, experience, and the utility of knowledge. Thus, using a western research paradigm, we recognize that Indigenous Knowledge cannot be adequately embodied in the form of knowledge production used here that relies heavily on rapid, written, and systematic information-gathering that is only weakly tied to longstanding experiences of place (Berkes, 2012; Cochran et al, 2013; Huntington \& Watson, 2012).

\section{Results}

\section{System Model of Modern Traditional Harvest Practices}

Developing a common understanding of key concepts around healthy traditional harvest practices, vulnerability, adaptive strategies, and resilience was 
an important component of the workshop process. Ten thematic areas or attributes of healthy traditional harvest practices emerged from the network mapping activity, and two additional attributes were added during the trend-mapping exercise, including the role that the cash economy and formal education system have in helping or hindering traditional harvest practices. Each cluster of word pairs was given a unique label agreed upon by the whole group. Results from the network mapping exercise are highlighted in Table 1 under the heading "Interior Alaska dimensions of healthy traditional harvest practices."

Using the trend-mapping exercise, participants

\section{Table 1. Comparing the Inuit Circumpolar Council (ICC)'s Six Dimensions of Food Security to Components of Healthy Traditional Harvest Practices of Rural Indigenous Communities in Interior Alaska Identified in the Workshop}

Availability (ICC definition): The ability of the Arctic ecosystem to maintain a high variety of life (biodiversity), allowing adequate transfer of nutrients and energy. It is the knowledge of the seasons and how to collect, process, store, and consume traditional foods, allowing for Inuit to eat what has been gathered from the previous seasons and harvest a variety of medicines (ICC, 2015, p. 34).

Interior Alaska dimensions of healthy harvest practices (workshop food security concepts)

Natural Grub Box: Includes concepts of harvest abundance of fish and game, healthy ecosystem, and quality of habitat.

Full Belly: Includes concepts of having enough, e.g., full smokehouse, winter supply, full cache, full freezer, abundance, and wealth.

Accessibility: The ability to live off the land, ocean, and air and to obtain sufficient access to a diverse source of healthy food, water, animals, plants, fish, ice, etc. The ability to maintain Inuit traditional economic practices, such as trading, sharing, and providing foods and medicines. It is the ability to access and maintain an economic system based on cash in connection to an Inuit traditional economic system. It is the ability to obtain skills, tools, and technologies needed to collect, process, and store traditional foods (ICC, 2015, p. 35)

Interior Alaska dimensions of healthy harvest practices

Corresponding positive and negative changes driving food security (FS) and insecurity (FI) in Interior Alaska

River Eddy and Hunting Trails: Includes concepts of good or easy access, cash needed to get out, opportunity, protection of resources, and reduced legal restrictions that limit access.

Cash economy: Harvest activities are now interdependent with the cash economy.

Inuit Culture: Food is the cornerstone of our culture and self and shared identity. Harvesting traditional foods is how cultural values, skills and spirituality are learned-this is how all learn to be within their environments and to be part of the ecosystem. The relationship between Inuit and all else that makes up the Arctic environment aids in the maintenance of cultural and environmental integrity (ICC, 2015, p. 34).

Interior Alaska dimensions of healthy harvest practices

Traditional Knowledge Practices: Includes concepts of preparing, understanding, getting an early start, teaching youth, and traditional practices.

Values: Includes concepts of spirituality, way of life, and strong culture.

Sharing: Includes concepts of unity, interdependence, community, cooperation, and distribution.
Better tools: rifles, gear, boats, snow machines (FS)

High fuel, energy, and equipment costs (FI)

Competition from outsider hunter/ fishers $(\mathrm{FI})$

Development pressures (FI)

Commercial fishing \& guiding $(\mathrm{FI})$
Corresponding positive and negative changes driving food security (FS) and insecurity (FI) in Interior Alaska

Youth culture camps (FS)

Language revitalization (FS)

Cultural resurgence (FS)

General sovereignty efforts (FS)

More respect for others and culture (FS)

Loss of Elders and their knowledge (FI)

Drugs \& alcohol (FI)

Culture disruptions (FI)

Influence of technology (FI) 
Health and Wellness: Physical health of all life within the Arctic and of the land, water and air; adequate passage and absorption of nutrients throughout the Arctic ecosystem; mental health related to community and household relations and self- and cultural identity; environmental integrity and productivity to withstand pollution, habitat destruction and other disturbances (ICC, 2015, p. 34).

\begin{tabular}{ll}
\hline Interior Alaska dimensions of healthy harvest practices & $\begin{array}{l}\text { Corresponding positive and negative } \\
\text { security (FS) and insecurity (FI) in Interc }\end{array}$ \\
\hline Happy, Strong Families: Includes concepts of teaching & Being together (FS) \\
children, respect, family, hard work, healthy food, & End of intergenerational trauma (FS) \\
generational sharing, exercise, and Elders. & Less participation in fish camp (FI) \\
& $\begin{array}{l}\text { Electronic technology (FI) } \\
\text { Increased individualism (FI) }\end{array}$
\end{tabular}

Stability: The ability of systems to adjust to each other as shifts within the ecosystem occur. The ability to maintain sustainability through the management of human actions that support and ensure younger generations will have sufficient healthy food to harvest and that all the pieces of the puzzle maintain connections. Stability is obtained through a level of Alaskan Inuit mental security and is in reference to the legal protections for environment against harm caused by pollutants. Mental security is also in reference to legal protection against forced assimilation, which allows for the maintenance of a level of cultural confidence and hope (ICC, 2015, p. 35).

Interior Alaska dimensions of healthy harvest practices

Environmental Conditions: Includes concepts of stability in climate, weather, and river navigability.

Formal Education System: Improves with greater Indigenous influence.
Corresponding positive and negative changes driving food security (FS) and insecurity (FI) in Interior Alaska

Increased Indigenous influence in western education system (FS)

Poor cultural integration that reinforced existing power structures (FI)

Climate change (FI)

Warmer winters (FI and FS)

Chanel and water level changes (FI and FS)

Riverbank erosion (FI)

Permafrost thaw (FI)

Unpredictable environment (FI)

Pollution (FI)

Fewer berries (FI)

Decision-Making Power and Management: The Alaska Inuit ability to use and value Indigenous Knowledge (IK) to manage daily activities; to build and rely on self-governance across space and time; for Alaska Inuit to use their knowledge system in synergy with other knowledge systems such as Western science, to equitably manage human activities within the Arctic environment and to better understand changes occurring; to apply holistic knowledge to understanding the Arctic environment through IK philosophies and methodologies; the ability to manage activities within the Arctic in a way that ensures younger generations will have healthy and nutritious foods to harvest; for Alaskan Inuit to have control over their own fate and to use their cultural value system (ICC, 2015, p. 34).

Interior Alaska dimensions of healthy harvest practices

Indigenous Governance: Includes concepts of stewardship, sustainability, insight, and conservation.

Western Governance: Includes concepts of power, management, law, agency, and strategy.
Corresponding positive and negative changes driving food security (FS) and insecurity (FI) in Interior Alaska

Cooperation/Collaboration (FS)

Co-Management structures (FS)

Increased advocacy (FS)

Increased capacity through Tribal Management (FS)

Traditional Ecological Knowledge (TEK) accepted as a methodology (FS)

Conservation efforts that protect wild food resources (FS)

Decrease in state funding for management (FS and FI)

Lack of involvement in process (FI)

Poor dual-management (FI)

Regional corporation priorities (FI)

Climate denial in politics (FI)

Note: $\mathrm{FS}=$ food security, $\mathrm{FI}=$ food insecurity. All results are displayed as written by individual workshop participants. 
were asked to identify the most significant positive and negative changes within the last 10 years that have affected the attributes of healthy traditional harvest practices identified during the first exercise. A total of 138 changes were generated. Of these changes, 61 were considered positive and 77 were considered negative. Changes that were identical or indicated a similar concept were grouped together and given a unique code by a subset of workshop participants. A total of 47 unique codes were identified, of which 20 were considered positive, 24 negative, and three were both positive and negative (Table 1). Positive changes corresponded to drivers of food security, while negative changes corresponded to drivers of food insecurity. Changes were grouped according to the six categories defined by the ICC as strong influences on traditional harvest system.

\section{A Holistic Definition of Healthy Traditional Harvest Practices for Rural Indigenous Communities in Interior Alaska}

Based on the discussion and content produced by CRP workshop participants, a holistic definition of food sovereignty for rural Indigenous communities in Interior Alaska began to emerge in connection with traditional harvest practices. Abundant fish, game, and wild foods provided through quality habitat and healthy ecosystems support full bellies, abundance, and wealth (Availability). Accessing this abundance is supported through stable environmental conditions, the cash needed to acquire the materials and supplies used to harvest wild resources, and the legal protection to hunt and fish within traditional territories (Accessibility). Abundance of wild foods and the continued ability to access them support the knowledge, values, and spirituality rooted in a strong culture that supports a way of life embodied through sharing, interdependence, and cooperation (Culture). The availability of wild foods and the traditional knowledge needed to harvest these resources effectively and appropriately support happy, strong families by supporting strong identities, physical wellness, and mental wellbeing (Health and Wellness). Indigenous influence on formal and informal forms of education will support future generations in acquiring the traditional knowledge and skills needed to maintain and adapt this way of life as social, economic, and environmental shifts occur (Stability). Indigenous governance structures that embody stewardship of the land, insight into the interconnections between people, animals, and place are paramount in the sustainability of wild foods and support self-governance and the management of wild resources (Decision Making Power and Management).

\section{Similar Definitions of Food Sovereignty}

Components of food sovereignty identified in the ICC food security conceptual framework include "type of management used, legal structures to support decision-making power, power dynamics, federal and state jurisdictions, equality of knowledge systems, the generation of information to inform decisions through co-production of knowledge and community-driven research" (ICC, 2015, p. 47). These components of food sovereignty have several similarities with the top 10 drivers of food security identified during the CRP workshop (Table 1), which include traditional knowledge practices, collaboration/cooperation, increased capacity in tribal management, TEK as a legitimate source of information, general sovereignty efforts, increased Indigenous influence in western systems, language revitalization, better science and Indigenous governance. Both the ICC-identified drivers of food sovereignty and those identified by the CRP workshop participants emphasize the need for changes in power dynamics and more Indigenous involvement in the decision-making processes that govern traditional and wild foods.

\section{Research and Partnerships that Strengthen Food Security and Sovereignty}

A substantive portion of the workshop focused on sharing results and reflections on research partnerships that had been developed over the previous two years. Workshop participants were asked to reflect on ways that individual partnerships strengthened drivers of food security or worked toward addressing drivers of food insecurity according to the definitions that were created together. Common themes that arose include the role that research partnerships play in supporting community-based adaptations through increased capacity in tribal management related to hunting, 
fishing, and gathering practices. It was also acknowledged that individual partnerships support climate change awareness, preparedness, and adaptation strategies. The emphasis on traditional harvest practices was acknowledged as important for supporting cultural resurgence. Cultural practices such as sharing, wise stewardship of resources, and language were all acknowledged for their significance in strengthening community resilience and adaptive capacity in response to change.

\section{Discussion}

\section{Comparison with Commonly Accepted Definitions of Food Security}

The FAO acknowledges four pillars of food security: availability, ${ }^{2}$ access, ${ }^{3}$ utilization, ${ }^{4}$ and stability ${ }^{5}$ (FAO, 2006). While three of the four pillars are similar in name to those developed within the ICC framework, the definitions differ in important ways. The FAO definition acknowledges the need for sufficient, quality food but does not include the roles of healthy ecosystems and the knowledge needed to gather and process food, whereas these concepts are included in the ICC and Interior Alaska definitions of health of traditional harvest practices developed in the workshop. General concepts of accessibility were consistent across the definitions. Both frameworks highlight the importance of resilient food systems that can withstand shocks from both environmental and social causes and remain stable. However, both the ICC and Interior Alaska healthy traditional harvest practices definitions emphasize in addition the mental health importance of protection from forced assimilation through institutionalized forms of edu- cation that threaten or undermine the stability of cultural knowledge and practices that support food security. There are some similarities between the FAO pillar of 'utilization' and the ICC dimension of food security 'health and wellness.' Both acknowledge the need for adequate and appropriate food that support nutrition and psychological needs. The FAO food security framework does not include specific provisions for culture nor decisionmaking power and management as aspects of food security.

\section{Alask Indigenous Food Sovereignty and Security}

It is important to note that presenting results from a workshop of contemporary perceptions of traditional harvest practices does not create an authoritative definition of food security among Indigenous communities of Interior Alaska, which would necessarily require broader input and consensus through the entire region. However, these results do illuminate the unique characteristics of food security, insecurity, and sovereignty that can provide a foundation for effective communitybased adaptations.

Broadening the commonly accepted definition of food security to include food sharing, the health of ecosystems, decision-making power, and culture as it relates to Indigenous communities in Alaska is an important step toward supporting communitybased adaptations. Relying on and sharing of fish, wildlife, and other harvested resources continue to be an integral part of physical, mental, and spiritual wellness, education, socio-economic development, and cultural identity. The practices and knowledge needed to harvest wild resources strengthen both food security and overall adaptive capacity of

\footnotetext{
2 "Food availability: The availability of sufficient quantities of food of appropriate quality, supplied through domestic production or imports (including food aid)" (FAO, 2006, p. 1).

3 "Food access: Access by individuals to adequate resources (entitlements) for acquiring appropriate foods for a nutritious diet. Entitlements are defined as the set of all commodity bundles over which a person can establish command given the legal, political, economic and social arrangements of the community in which they live (including traditional rights such as access to common resources)" (FAO, 2006, p. 1).

4 "Utilization: Utilization of food through adequate diet, clean water, sanitation and health care to reach a state of nutritional wellbeing where all physiological needs are met. This brings out the importance of non-food inputs in food security" (FAO, 2006, p. 1). 5 "Stability: To be food secure, a population, household or individual must have access to adequate food at all times. They should not risk losing access to food as a consequence of sudden shocks (e.g. an economic or climatic crisis) or cyclical events (e.g. seasonal food insecurity). The concept of stability can therefore refer to both the availability and access dimensions of food security" (FAO, 2006, p. 1).
} 
Indigenous communities in Alaska (Barnhardt \& Kawagley, 2005; CATG, 2016). The body of knowledge contained in traditions among tribal members and Elders can provide sources of strength and guidance to communities as they face current and future change (Watson \& Huntington, 2014).

Another important step in supporting community-based adaptations is building institutional mechanisms that can support Indigenous communities effectively as they continue to navigate complex change. With the interconnections between traditional harvest practices, the cash economy, western education, and western governance systems, effective community-based adaptations cannot be accomplished without engaging in these contemporary western systems. Navigating these systems today requires capacity development beyond the breadth of knowledge gained through participation in hunting, fishing, and gathering practices alone. It now also requires an in-depth knowledge of current regulatory systems, an understanding of how policies are developed, and the ability to formulate and articulate evidence-based proposals that fit institutional requirements or charters on local, statewide, and national scales. Communities must also consider tradeoffs between conservation initiatives that serve to protect traditional harvest species and the habitats they rely on with economic development initiatives that exploit these resources but provide much needed economic opportunity not easily gained in remote rural communities. Consideration of the economic dimension is important because many rural communities rely on cash input to carry out their traditional harvest practices (Brinkman et al., 2014). For example, affordable gasoline is needed to fuel boats, snowmobiles, and ATVs used to access traditional harvest areas.

\section{Role of Multistakeholder Partnerships in Supporting Community-based Adaptations}

By creating a holistic, place-based definition of food sovereignty and identifying factors that contributed to both food security and insecurity, CRP workshop participants came away with a tool that validated their experiences and perspectives. This framework illuminated ways that tribes and tribal organizations were already actively advancing food sovereignty by participating in cultural activities such as revitalizing their language, maintaining sharing practices, and continuing to pass down knowledge of hunting and fishing practices to the next generation. It also showed the value of existing advocacy efforts related to hunting and fishing management decisions. The framework highlighted areas where individual research partnerships and broader research initiatives led by collaborators contributed to strengthening food security or responded to different components of food insecurity. For example, mapping traditional place names was identified as significant for not only facilitating the transfer of knowledge between generations, but also providing a resource for state-led land-use planning decisions that would affect traditional use areas. Another study focused on the correlation between temperature, water levels, timing of leaf fall, and moose harvest success. This research was requested by a participating tribe in response to an unsuccessful proposal to a regulatory body that advocated for more adaptive timing of hunting seasons that would take into account the influence of climate variables on harvest success. The resulting research provided useful data to the tribe as they continue to advocate for adaptive management of natural resources.

Although these individual research partnerships and a place-based definition of food sovereignty alone do not lend themselves to suggesting sweeping policy changes, they are examples of ways that community-based adaptations can occur in practice. They highlight the learning process that is integral to adapting to unprecedented change.

Due to the complexity of historical socioeconomic factors, and the variability of the ways that climate change will affect different geographic areas, onesize-fits-all solutions are problematic. However, a supporting mechanism that can bridge diverse perspectives, capacities, and areas of influence is a replicable process that can support community-based adaptations (Reid et al., 2009).

Given the interconnected dimensions and complexity of food sovereignty and security, developing mechanisms that support co-production of knowledge, two-way communication and learning among communities, academic entities, agencies, 
and nonprofit organizations supports capacitybuilding among community leaders to navigate the current management, economic, and educational systems (Ford, McDowell, \& Pearce, 2015). It also builds capacity among university researchers and resource managers to do work that is important to, and owned by, communities. In addition, this process can build institutional capacity that promotes inclusion of different ways of knowing within nonIndigenous institutions. Groups like Community Research Partnerships for Sustainable Traditional Harvest Practices support the development of such forums. Multistakeholder partnerships can support community-based adaptations by building bridges between Indigenous communities and the tribal organizations that represent them with formal educational institutions, natural resources managers, and policy-makers-all of which influence food security according to the definition developed by CRP workshop participants. Taken together, community, multidisciplinary academic, and agency partnerships provide a mechanism for developing social and communication networks that provide channels for new creative forms of learning and knowledge distribution. These networks can support communities as they negotiate the effects of current and future changes to maintain basic components of standards of living such as food security (Chapin, Knapp, Brinkman, Bronen, \& Cochran, 2016). They also can change the way science is done at universities and agencies so that it is more relevant, credible, and legitimate for society (Reid et al., 2016).

\section{Conclusions}

In the growing body of adaptation literature, particularly as it relates to Indigenous peoples of the North, there are frequent calls for supporting bottom-up, stakeholder-driven, community-based, and co-produced adaptation solutions that can account sufficiently for the interwoven social-ecological relationships developed through a long-standing interdependence on wild foods (Ford et al., 2018; Loring \& Gerlach, 2009; McNeely, 2011; Pearce et.al, 2014). Despite this acknowledgment, there are few studies that put this into practice (Loring \& Gerlach, 2015). Our work highlights the valuable insights that are gained when those communities and individuals who stand to be most affected by rapid change are also the ones who identify the framework for developing possible solutions.

Food sovereignty by definition carries inherent meanings of autonomy, authority, and selfgovernance. Defining the components of food practices in relation to a physical environment, specific culture, and jurisdiction of place is a necessary building block in strengthening food sovereignty, particularly as it relates to Indigenous communities in Alaska (Grey \& Patel, 2015). The ICC food sovereignty and security framework, the healthy traditional harvest practices framework, and the definitions developed by CRP workshop participants all emphasize that food security means much more than nutritional value, caloric intake, and purchasing power. A vision of food sovereignty and security for Indigenous people in Alaska encompasses a holistic picture of ecological health and stability, practicing and transmitting a way of life to the next generation, political protection and freedom to maintain culturally based livelihoods, and the freedom to select and integrate adaptations consistent with a way of life in response to current and future environmental, economic, political, and social change. As aptly stated by co-author Huntington, "as tribal people, we have the right to be who we are." Developing a holistic definition of food security is a critical first step toward reaching a regional Indigenous consensus on a formal definition that may inform policy. It also provides a useful reference for developing research in the future that strengthens, rather than diminishes, the capacity of communities to adapt effectively to change.

\section{Acknowledgments}

We gratefully acknowledge the contributions of Tanana Chiefs Conference Hunting and Fishing Task Force, and Department of Wildlife and Parks for their commitment and long-term investment in the food security and sovereignty of tribes throughout Interior Alaska. We also acknowledge all those who have contributed to the Community Research Partnership for Sustainable Traditional Harvest Practices initiative who were not able to participate in the CRP workshop, but whose input and involvement have guided the process through- 
out. Although there are too many to include here, we would like to specifically thank tribal members from the Anvik Tribal Council, Koyukuk Tribal Council, Nulato Tribal Council, Ruby Tribal Council, and Venetie Tribal Council. We also acknowl- edge the contributions of the University of Alaska Fairbanks, rural Interior Alaska Campus Tribal Management program and the Council of Athabascan Tribal Governments for their leadership in and involvement with this work.

\section{References}

Alaska National Interest Lands Conservation Act (ANILCA) of 1980. 16 U. S. C. Ch. 51 \ 3101 et seq. (1980).

Alaska Native Claims Settlement Act (ANCSA) of 1971. 43 U. C. S. Ch. 33 \& 1603 et seq. (1971).

Alaska Native Knowledge Network (ANKN). (2000). Guidelines for respecting cultural knowledge. Anchorage, AK: ANKN. Retrieved from http://ankn.uaf.edu/Publications/Knowledge.pdf

Alaska Native Science Commission (ANSC). (1997). Code of research ethics sample. Anchorage, AK: ANSC. Retrieved from http://www.nativescience.org/communities/code.htm

Anderson, S. A. (Ed.). (1990). Core indicators of nutritional state for difficult-to-sample populations. The Journal of Nutrition, 120(Suppl. 11), 1557S-1600S. https://doi.org/10.1093/in/120.suppl 11.1555

Barnhardt, R., \& Kawagley, A. O. (2005). Indigenous knowledge systems and Alaska native ways of knowing. Anthropology and Education Quarterly, 36(1), 8-23. https://doi.org/10.1525/aeq.2005.36.1.008

Berkes, F. (2012). Sacred ecology (3rd ed.). New York: Routledge.

Brinkman, T. J., Hansen, W. D., Chapin, F. S., III, Kofinas, G., BurnSilver, S., \& Rupp, T. S. (2016). Arctic communities perceive climate impacts on access as a critical challenge to availability of subsistence resources. Climatic Change, 139(3-4), 413-427. https://doi.org/10.1007/s10584-016-1819-6

Brinkman, T., Maracle, K., Kelly, J., Vandyke, M., Firmin, A., \& Springsteen, A. (2014). Impact of fuel costs on highlatitude subsistence activities. Ecology and Society, 19(4), 18. https://doi.org/10.5751/ES-06861-190418

Brown, D. R., Brinkman, T. J., Verbyla, D. L., Brown, C. L., Cold, H. S., \& Hollingsworth, T. N. (2018). Changing river ice seasonality and impacts on interior Alaska communities. Weather, Climate, and Society, 10(4), 625-640. https://doi.org/10.1175/WCAS-D-17-0101.1

Chapin, F. S., III, Knapp, C. N., Brinkman, T. J., Bronen, R., \& Cochran, P. (2016). Community-empowered adaptation for self-reliance. Current Opinion in Environmental Sustainability, 19, 67-75. https://doi.org/10.1016/j.cosust.2015.12.008

Chapin, F. S., III, Trainor, S. F., Cochran, P., Huntington, H., Markon, C., McCammon, M., McGuire, A. D., \& Serreze, M. (2014). Alaska. In J. M. Melillo, T. C. Richmond, \& G. W. Yohe (Eds.), Climate change impacts in the United States: The third national climate assessment (pp. 513-536). Washington, DC: U. S. Global Change Research Program. https://doi.org/10.7930/J00Z7150

Cochran, P., Huntington, O. H., Pungowiyi, C., Tom, S., Chapin III, F. S., Huntington, H. P., Maynard, N. G., \& Trainor, S. F. (2013). Indigenous frameworks for observing and responding to climate change in Alaska. Climatic Change, 120(3), 557-567. https://doi.org/10.1007/s10584-013-0735-2

Comiso, J. C., \& Hall, D. K. (2014). Climate trends in the Arctic as observed from space. WIREs Climate Change, 5(3), 389-409. https://doi.org/10.1002/wcc. 277

Coté, C. (2016). "Indigenizing" food sovereignty. Revitalizing Indigenous food practices and ecological knowledges in Canada and the United States. Humanities, 5(3), 57. https://doi.org/10.3390/h5030057

Council of Athabascan Tribal Governments (CATG). (2016). Bridging yesterday with tomorrow: Understanding traditional ecosystem management practices and their application to contemporary sustainable boreal ecosystem management. Fort Yukon, AK: CATG \& Northwest Boreal Landscape Conservation Cooperative. Retrieved from https://www.catg.org/wp-content/uploads/2017/06/index 2 3842744447.pdf

Djenontin, I., \& Meadow, A. (2018) The art of co-production of knowledge in environmental sciences and management: Lessons from international practice. Environmental Management, 61(6), 885-903. https://doi.org/10.1007/s00267-018-1028-3

Duhaime, G. (Ed.). (2002). Sustainable food security in the Arctic: State of knowledge. Quebec City, QC: Canadian Circumpolar Institute Press. 
First Alaskans Institute (FAI). (2014). Advancing native dialogues on racial equity. Anchorage, AK: Author. Retrieved from https:// firstalaskans.org/alaska-native-policy-center/racial-equity/

Food and Agriculture Organization of the United Nations (FAO). (2006). Food security (Policy Brief Issue 2). Rome: FAO Agriculture and Development Economics Division. Retrieved from http://www.fao.org/fileadmin/templates/faoitaly/documents/pdf/pdf Food Security Cocept Note.pdf

Foote, D. C. (1965). Exploration and resource utilization in Nortbwestern Arctic Alaska before 1855 (Doctoral dissertation). Montreal: McGill University, Department of Geography. Retrieved from http://digitool.library.mcgill.ca/R/?func=dbin-jump-full\&object id=117771\&local base=GEN01-MCG02

Ford, J. D., McDowell, G., \& Pearce, T. (2015). The adaptation challenge in the Arctic. Nature Climate Change, 5, 1046-1053. https://doi.org/10.1038/nclimate2723

Ford, J. D., Sherman, M., Berrang-Ford, L., Llanos, A., Carcamo, C., Harper, S., .. \& Edge, V. (2018). Preparing for the health impacts of climate change in Indigenous communities: The role of community-based adaptations. Global Environmental Change, 49, 129-139. https://doi.org/10.1016/i.gloenvcha.2018.02.006

Grey, S., \& Patel, R. (2015). Food sovereignty as decolonization: Some contributions from Indigenous movements to food system and development politics. Agriculture and Human V alues, 32(3), 431-444. https://doi.org/10.1007/s10460-014-9548-9

Huntington, O. H., \& Watson, A. (2012). Interdisciplinarity, Native resilience, and how the riddles can teach wildlife law in an era of rapid climate change. Wicazo Sa Review, 27(2), 49-73. https://doi.org/10.5749/wicazosareview.27.2.0049

Inuit Circumpolar Council-Alaska (ICC). (2015). Alaskan Inuit food security conceptual framework: How to assess the Arctic from an Inuit perspective [Technical report]. Anchorage, AK: ICC-Alaska. Retrieved from http://iccalaska.org/wp-icc/wp-content/uploads/2016/05/Food-Security-Full-Technical-Report.pdf

Kawagley, A. O. (2006). A Yupiaq worldview: A pathway to ecology and spirit (2 $2^{\text {nd }}$ ed.). Long Grove, IL: Waveland Press.

Kepkiewicz, L., Chrobok, M., Whetung, M., Cahuas, M., Gill, J., Walker, S., \& Wakefield, S. (2015). Beyond inclusion: Toward an anti-colonial food justice praxis. Journal of Agriculture, Food Systems, and Community Development, 5(4), 99-104. https://doi.org/10.5304/jafscd.2015.054.014

Krauss, M. E. (1982). Indigenous peoples and languages of Alaska. Anchorage: Alaska Native Language Center, University of Alaska. Retrieved from http://www.alaskool.org/language/languagemap/index.html

Krupnik, I. (1993). Arctic adaptation: Native whalers and reindeer herders of northern Eurasia (Trans. \& ed. M. Levenson). Hanover, N.H.: University Press of New England.

Larsen, J. N., Anisimov, O. A., Constable, A., Hollowed, A. B., Maynar, N., Prestrud, P., . . Stone, J. M. R. (2014). Polar regions. In V. R. Barros, C. B. Field, D. J. Dokken, M. D. Mastrandrea, K. J. Mach, T. E. Bilir, . . L. L. White (Eds.), Climate change 2014: Impacts, adaptation, and vulnerability. Part B: Regional aspects. Contribution of Working Group II to the fifth assessment report of the Intergovernmental Panel on Climate Change (pp. 1567-1612). Cambridge, UK, \& New York: Cambridge University Press.

Leblond, M., St-Laurent, M.-H., \& Côté, S. D. (2016). Caribou, water, and ice-Fine-scale movements of a migratory Arctic ungulate in the context of climate change. Movement Ecology, 4, Art. 14. https://doi.org/10.1186/s40462-016-0079-4

Loring, P., \& Gerlach, S. C. (2009). Food, culture, and human health in Alaska: An integrative health approach to food security. Environmental Science \& Policy, 12(4), 446-478. https://doi.org/10.1016/i.envsci.2008.10.006

Loring, P., \& Gerlach, S. C. (2015). Searching for progress on food security in the North American North: A research synthesis and meta-analysis of the peer-reviewed literature. Arctic, 68(3), 380-392. https://doi.org/10.14430/arctic4509

Loyens, J. (1966). The changing culture of the Nulato Koyukon Indians. Fairbanks: University of Alaska Press.

McNeely, S. (2011). Examining barriers and opportunities for sustainable adaptation to climate change in Interior Alaska. Climatic Change, 111(3-4), 835-857. https://doi.org/10.1007/s10584-011-0158-x

Naske, C. M., \& Hunt, W. R. (1978). The politics of bydroelectric power in Alaska: Rampart and Devil Canyon-A case study. Fairbanks: University of Alaska, Institute of Water Resources. Retrieved from https://www.arlis.org/docs/vol1/Susitna/40/APA4090.pdf 
National Congress of American Indians Policy Research Center \& Montana State University Center for Native Health Partnerships. (2012). 'Walk softly and listen carefully': Building research relationships with tribal communities. Washington, D.C. \& Bozeman, MT: NCAI and MSU. Retrieved from http://www.ncai.org/resources/ncai publications/walk-softlyand-listen-carefully-building-research-relationships-with-tribal-communities

National Research Council, Committee on Evaluation of 1950s Air Force Human Health Testing in Alaska Using Iodine-131. (1996). The Arctic aeromedical laboratory's thyroid functional study: A radiological risk and ethical analysis. Washington, D.C.: National Academies Press. https://doi.org/10.17226/5106

North Slope Borough Science Advisory Committee. (1993). A review of the "Project Chariot: 1962 tracer study remedial action plan” by U.S. Department of Energy Nevada field office environmental restoration division (Log number 93-085). Fairbanks: University of Alaska, School of Fisheries and Ocean Sciences. Retrieved from http://www.northslope.org/assets/images/uploads/1993 Project Chariot 1962 Tracer Study Remedial Action Plan.pdf

Nyéléni Forum on Food Sovereignty. (2007). Declaration of Nyéléni. Sélingué, Mali: Forum on Food Sovereignty. Retrieved from https://nyeleni.org/spip.php?article290

Parkhurst, M., \& Preskill, H. (2016). Guide to trend mapping: A tool for supporting systems thinking. Washington, D.C.: FSG Reimagining Social Change. Retrieved from https://www.fsg.org/tools-and-resources/guide-trend-mapping\#download-area

Pearce, T., Ford, J., Willcox, A.C., \& Smit, B. (2014). Inuit traditional ecological knowledge (TEK), subsistence hunting and adaptation to climate change in the Canadian Arctic. Arctic, 68(2), 141-282. https://doi.org/10.14430/arctic4475

Reid, H., Mozaharul, A., Berger, R., Cannon, T., Huq, S., \& Milligan, R. (2009). Community-based adaptation to climate change: An overview. International Institute of Environment and Development. Participatory Learning and Action, 60(1), 11-33. Retrieved from http://pubs.iied.org/pdfs/G02608.pdf

Reid, R. S., Nkedianye, D., Said, M. Y., Kaelo, D., Neselle, M., Makui, O., ... Clark, W. C. (2016). Evolution of models to support community and policy action with science: Balancing pastoral livelihoods and wildlife conservation in savannas of East Africa. Proceedings of the National Academy of Science, 113(17), 4579-4584. https://doi.org/10.1073/pnas.0900313106

Ristroph, E. B. (2018). How can laws, institutions, and plans facilitate Alaska Native village adaptation to climate change? (Doctoral dissertation). University of Hawaii, Manoa. Retrieved from https://ristroph.wordpress.com/articles/

Sbicca, J. (2015). Solidarity and sweat equity: For reciprocal food justice research. Journal of Agriculture, Food Systems, and Community Development, 5(4), 63-67. https://doi.org/10.5304/jafscd.2015.054.004

Watson, A., \& Huntington, O. (2014). Transgressions of the man on the moon: Climate change, Indigenous expertise, and the post-humanist ethics of place and space. GeoJournal, 79(6), 721-736. https://doi.org/10.1007/s10708-014-9547-9

Weiler, A. M., Hergesheimer, C., Brisbois, B., Wittman, H., Yassi, A., \& Spiegel, J. (2014). Food sovereignty, food security and health equity: A meta-narrative mapping exercise. Health Policy and Planning, 30(8), 1078-1092. https://doi.org/10.1093/heapol/czu109

Wheeler, P., \& Thornton, T. (2005). Subsistence research in Alaska: A thirty year retrospective. Alaska Journal of Anthropology, 3(1), 69-103. Retrieved from http://www.alaskaanthropology.org/wp-content/uploads/2017/09/Vol 3 1-Paper-3-Wheeler-Thornton.pdf

Wittman, H., \& Blesh, J. (2017). Food sovereignty and Fome Zero: Connecting public food procurement programs to sustainable rural development in Brazil. Journal of Agrarian Change, 17(1), 81-105. https://doi.org/10.1111/joac.12131

Wolfe, R. J. (1982). Alaska's Great Sickness, 1900: An epidemic of measles and influenza in a virgin soil population. Proceedings of the American Philosophical Society, 126(2), 91-121. Retrieved from: https://www.jstor.org/stable/pdf/986355

Zagoskin, L.A. (1967). Lieutenant Zagoskin's travels in Russian America, 1842-1844: The first ethnographic and geographic investigations in the Yukon and Kuskokwim valleys of Alaska (Ed. M. N. Henry). Toronto: University of Toronto Press. 